\title{
Promotion and Renewal of the Outdoor Environment of the Collective Housing That Promotes Health
}

\section{-Based on the Post-Epidemic Perspective}

\author{
Jing Li, Yuanyuan Du*, Yajing Lei \\ School of Architecture and Art, North China University of Technology, Beijing, China \\ Email: *caicai_315@126.com
}

How to cite this paper: Li, J., Du, Y.Y. and Lei, Y.J. (2021) Promotion and Renewal of the Outdoor Environment of the Collective Housing That Promotes Health. Journal of Environmental Protection, 12, 1218-1233. https://doi.org/10.4236/jep.2021.1212072

Received: October 29, 2021

Accepted: December 28, 2021

Published: December 31, 2021

Copyright $\odot 2021$ by author(s) and Scientific Research Publishing Inc. This work is licensed under the Creative Commons Attribution International License (CC BY 4.0).

http://creativecommons.org/licenses/by/4.0/ (c) (i) Open Access

\begin{abstract}
The COVID-19 is a major global health event that has changed people's lives and behaviors. As a fragile and sensitive area with high population density and poor living conditions in the city, collective housing is also an important construction area for future urban renewal. In the process of the spread of the new crown epidemic, the collective housing has exposed a series of weaknesses such as difficult community management, inconvenience of life, and insufficient outdoor space. Therefore, the update and transformation of the outdoor environment of the collective housing combined with the concept of public health is a problem that must be considered at present. This article combines the practice of renewal and transformation of the $\mathrm{X}$ community in Chaoyang District, Beijing, combined with survey methods such as questionnaires, interviews, and observations, combined with the needs of residents and the practical experience of the grassroots management unit, and carried out an overall renewal design of the external space environment of the collective housing. The epidemic is combined with the division of functional layout, refined design of outdoor activity space to ensure safe distance, and increased shared smart facilities to improve the quality of the outdoor environment of collective residences and strengthen community resilience; to achieve communication and sharing, epidemic prevention and control on the basis of ensuring safe social distance outdoor sports and other functions. In this way, the ability of collective housing to prevent, identify, and dispose of urban risks will be improved, and will provide residents with a better and livable community life.
\end{abstract}

\section{Keywords}

Health, Collective Housing, Outdoor Environment Renewal, 
Post-Epidemic

\section{Research Background}

\subsection{The Problems Exposed in the Epidemic in the Collective Residential Community Need to Be Rectified Urgently}

Coronavirus - a large family of viruses that range in severity from colds to severe illnesses such as Middle East Respiratory Syndrome (MERS) and Severe acute respiratory syndrome (SARS) - novel Coronavirus is a new strain of coronavirus-that has not been previously identified in humans. Common signs of coronavirus infection include respiratory symptoms, fever, cough, shortness of breath and dyspnea. In more severe cases, the infection can lead to pneumonia, severe acute respiratory syndrome, kidney failure and even death.

During the outbreak, China took strong prevention and control measures, but the prevention and control of this epidemic has exposed many shortcomings of the outdoor environment of collective housing. China's urban collective housing generally has aging infrastructure, poor living environment, insufficient service facilities, and lack of property management. Therefore, in the context of epidemic prevention and control, higher requirements have been put forward for the transformation of urban collective housing [1]. During the severe period of the epidemic, the whole country adopts closed management from urban areas to villages and towns. The completeness of supporting facilities in a residential unit can directly affect the comfort level of residents' home isolation. For cities and towns, communities with relatively new buildings have sound properties and complete facilities, and the residents' life satisfaction has been improved. However, in the residential complexes with longer buildings, the external space configuration of the community no longer meets the needs of current residents, and a large amount of public space is occupied by private cars. Occupation, the population type within the community is complex, with self-occupied old people, migrants who rent a house due to location advantages, and traditional threeperson households buying houses due to the advantages of the school district and commuting as the main residents. The complexity of the population structure directly leads to the safety of the collective housing. It is not high, residents have a poor sense of participation and integration, and the community atmosphere is insufficient. Especially in the current situation of normalized management of the epidemic, the already cramped community public space is transformed into an epidemic prevention space, and disaster relief tents are set up for the community's daily temperature measurement and recording work. For example, Jinsong District 2 is a typical case of collective housing, with a total of 800,000 . The community area of 21 square meters has opened 21 doors, and the inter-area roads are highly integrated with the internal roads of the community. 
The access control measures of the epidemic have brought great inconvenience to the lives of residents. At the same time, children play in the green spaces around the roads where vehicles pass, which is extremely safe. Although the closed management of the collective housing cut off the transmission route of the epidemic, it also hindered the normal life style and social interaction of the residents to a certain extent. The problem of the collective housing exposed in the epidemic requires urgent attention and effective measures.

\subsection{The Epidemic Has Transformed the Lifestyles of Urban Residents}

In the two years since the outbreak of the new crown epidemic, people's social space and social distance have been affected to varying degrees, which directly led to a change in people's usual behavior paradigm. During the extraordinary period in February 2020, China recommended that residents maintain social distancing (also known as "safe distance") to reduce the spread of COVID-19. The epidemic prevention standards of different provinces are different, and the intensity of the measures issued varies. Some just close public places such as entertainment venues, bars, schools, and some areas directly adopt a policy of closing the city, requiring residents to stay at home and not go out unless necessary. During this period, social media such as the Internet developed rapidly, and online learning, office work, and social networking were being carried out almost all over the country. Related learning and office apps, such as MOOC, Tencent Conference, and WeChat, have gradually seized the market. Today, people still choose a combination of online and offline methods to carry out related work, and the communication distance between people has also tended to develop more flexibly.

In the post-epidemic period when the current prevention and control situation is stable, major entertainment venues have been reopened one after another. Short video social software accounts for most of people's spare time. The richness of leisure and entertainment activities has only increased compared with that before the epidemic, so special attention is needed. Vulnerable groups such as the elderly and young children who seldom use smartphones and occupy the space for outdoor activities in the traditional residential complex, lack of sufficient neighborhood communication, closeness to nature, and opportunities for outdoor activities will cause a series of psychological and physical problems. Ten years ago, the World Health Organization declared that lack of exercise was the fourth leading cause of death in the world, and the global incidence of insufficient physical activity was about $27.5 \%$.

Therefore, based on the geographical location of the sample, a total of 156 questionnaires were distributed through the PC to the residents of the surrounding communities in the early stage of the research. After removing the invalid questionnaires, 150 valid questionnaires were obtained, with an effective rate of $96 \%$. According to the questionnaire, over $97 \%$ of the interviewees live in collec- 
tive residences that have been built for more than 20 years. The residential floors are mainly middle and low-rise buildings. At the same time, these collective residences are mainly housed in houses that are normally bought and sold and houses allocated by the unit. type. In the family structure of residents, residents living with their spouses and children account for the majority, followed by those living with their spouses. At the age level, due to restrictions on the Internet, $68 \%$ of the respondents are under the age of 60 . However, according to offline actual data, this type of "collective housing with a construction period of more than 20 years" still consists of the elderly. Resident subject, as shown in Figure 1 .

Therefore, when China implements the comprehensive renovation work for collective housing in the post-epidemic period, it first needs to conduct a questionnaire survey on the surrounding area to understand the types and needs of residents, especially in the context of the post-epidemic period. The redefinition of the user's behavior pattern to re-evaluate the space paradigm of the block, residential area, and architectural design, re-examine the appropriate spatial scale, redefine the flexibility and adaptability of the space, and rethink the connection between the spatial planning and the user. Currently, planning research from the perspective of post-epidemic situation is still in its infancy. Subject competitions and academic conferences are the main focus, and there are few practical-level strategy studies. "The entrance hall" in the park community) focuses on the thinking and practice of micro-reconstruction in the community in the post-epidemic period.

\begin{tabular}{|c|c|c|}
\hline Gender distribution of respondents & Age distribution of respondents & The respondents live on different floors \\
\hline -Men & $\begin{array}{l}\text { - Under the age of } 17 \\
-18 \text { to } 35 \text { years } 010 \\
-36 \text { to } 60 \text { years old } \\
-61 \text { to } 70 \text { years odd } \\
\cdot \text { More than } 71 \text { year old }\end{array}$ & $\begin{array}{l}\text { - Under } 6 \text { layers } \\
7 \text { to } 10 \text { layers } \\
\text { 11 to } 18 \text { layers } \\
\text { - More than } 18 \text { layer }\end{array}$ \\
\hline Housing type distribution of respondents & Respondents living conditions distribution & Respondents housing area distribution \\
\hline $\begin{array}{l}\text {-Housing distribution } \\
\text {-Commercial housing } \\
\text {-Rental housing } \\
\text { - Other }\end{array}$ & $\begin{array}{l}\text { - Living alone } \\
\text { - Live with your spouse } \\
\text { - Live with their obilyen } \\
\text { - Live with grandchilgren } \\
\text { - Live with their spouses and chydren } \\
\text { - Live with their parents }\end{array}$ & $\begin{array}{l}-20 \text { to } 50 \text { squaremerers } \\
-50 \text { to } 90 \text { squaremerers } \\
-90 \text { to } 120 \text { squaremeters } \\
-120 \text { to } 200 \text { squaremeters }\end{array}$ \\
\hline
\end{tabular}

Figure 1. Statistics of the basic situation of the respondents. Image source: self-painted. 


\section{Combined with Existing Research on Promoting Public Health from the Perspective of Post-Epidemic}

Two years after the outbreak of the new crown epidemic, China and the world have been deeply aware of the importance of urban health and population health. Since the 21st century, mankind has been facing various health problems. The increase in global morbidity and mortality caused by epidemics or other infectious diseases has caused humans to reflect on their own health and living environment issues, including urban and community levels.

In the field of urban planning, health issues have always been the focus of attention of experts, and some Western scholars initially combined the living environment with population health. Around 2002, the relationship and influence between public health and the built environment of cities have gradually been paid attention to by experts and scholars in academia, conducting different degrees of research, and constructing relevant theoretical models for different disciplines and different factors. James F. Sallis and other scholars first conducted empirical research on this aspect [2]. Another wave of research was around 2005. Research in this period was mainly devoted to improving and sublimating the original theoretical basis. Various results began to be intensively and objectively proven, and a series of new proper terms and definitions appeared.

With the continuous development of various disciplines, in recent years, there have been some projects dedicated to large-scale measurement of specific health components in cities, especially in community environments. The ultimate goal is to connect them with the existing population, so as to carry out interdisciplinary collaborative research and provide evidence for the creation of healthy cities. For example, Cao X conducted a survey of 1553 residents in 8 communities in a certain area in the United States and found that more than half of the people's behavior in the built environment of the community can be interpreted as purposeful walking. Right, they still believe that walking type is related to the health level of the community [3].

Chinese scholars' research on residential health issues is later than in the West. The research on public health by Chen Luyao, Tan Shaohua and others has gradually matured in recent years. They have clarified the promotion of residents' health by green space elements, and pointed out that constructing open and evenly distributed community green spaces can well promote population health; second Based on the scale of people, designing community green spaces that are participatory for different age groups [4]. Scholars Dong Jingjing pointed out in his research literature that several factors of behavior change have a strong logical relationship with the spatial environment, and this logical relationship determines all the characteristics of the urban spatial level, the needs of healthy behavior [5]. Based on this theory, she puts forward the concept of a healthy living unit, and builds a community positioning that meets basic health needs by abstracting individual healthy behavior needs.

The research based on the perspective of public health has been relatively ma- 
ture, while the research on environmental factors from the perspective of epidemic situation after integration is relatively rare. Long Ying scholars summarize the evaluation system of residential communities from the perspective of public health [6], in view of its applicability in the post-epidemic period, he proposed housing The interaction between environment and lifestyle (transportation, work, recreation, residence) affects residents' behavior patterns (physical activities, mental activities, etc.). At present, the space and behavior of residents are restricted to a certain extent, but the resulting health risk factors (insomnia, depression, anxiety, etc.) need more detailed evaluation indicators to avoid and control. Therefore, the entry of "post-epidemic" is both an inhibitor and a catalyst. While paying more attention to the health of the external environment, it is necessary to control social distancing and spatial isolation.

\section{Sample Research and Current Situation Analysis}

\subsection{Sample Overview}

Community X is located in Chaoyang District, Beijing. It was built in 1983 in Dongba Township. There are 5 buildings, all of which are 5-storey high-slab buildings, with a brick-concrete structure. There are 240 residents in the community and the occupancy rate is $100 \%$, of which the elderly account for the total. More than $60 \%$ of the population; the community is a typical multi-residential surrounding layout (Figure 2), with small public space, mixed pedestrians and vehicles, aging facilities, and lack of barrier-free facilities; there are about 40 parking spaces in the community. The open space between the buildings is mainly for parking, with less greenery.

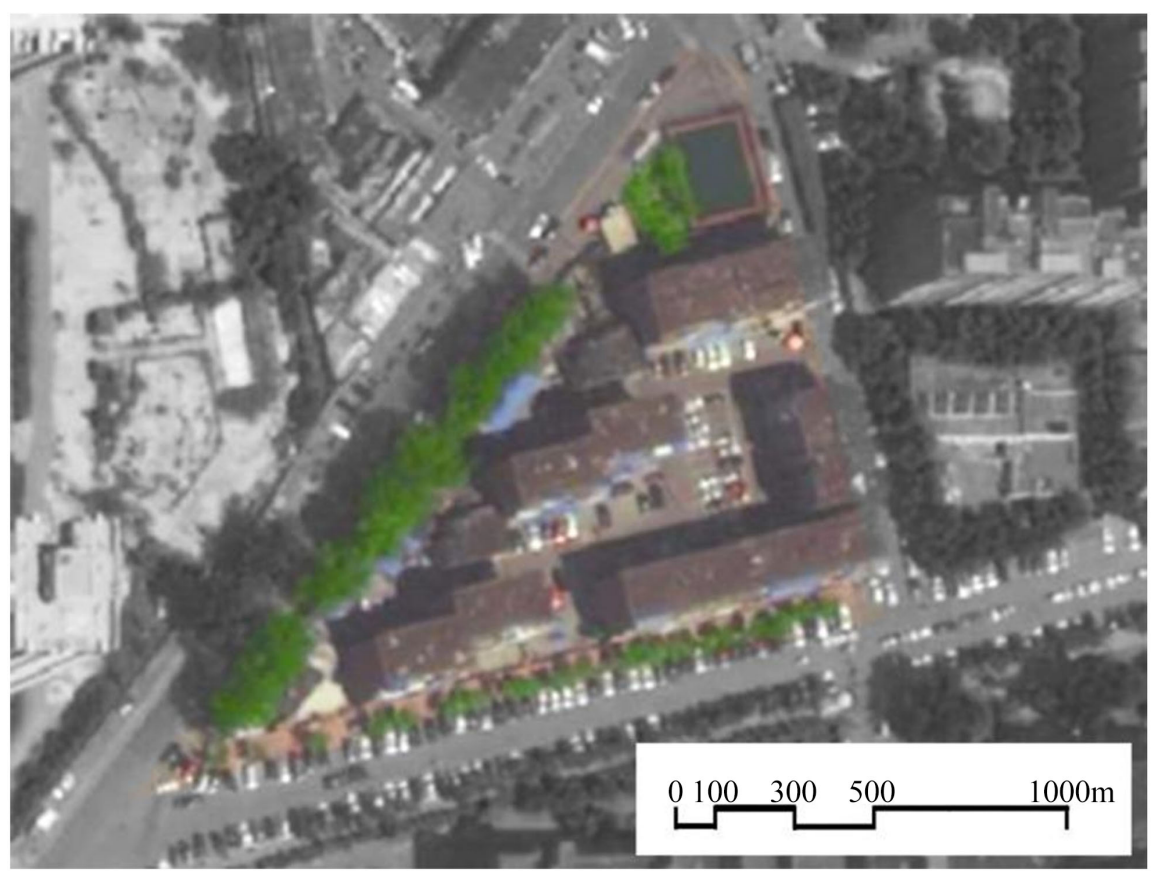

Figure 2. Real map of X community. Image source: Baidu map. 


\subsection{Main Issues}

Through on-site surveys, resident interviews and questionnaire surveys, the community $\mathrm{X}$ is divided into idle usable space, parking space and activity space by region, as shown in Figure 3. Under the epidemic situation, the team tried to jump out of the fixed transformation paradigm of collective housing. The model of external and beautification projects, facility additions, internal pipeline burying, and building reinforcement can no longer meet the current epidemic prevention and security needs.

\subsubsection{Space Cramps Cause Functional Chaos}

The public space in the small area is filled with parking spaces and lacks basic activity space. The entrance of the community was originally a space for the elderly to rest and enjoy the cool. Later, due to the needs of epidemic prevention and control, disaster relief tents were set up, which directly caused the elderly to have nowhere to enjoy the cool. The cramp and complexity of the above spaces have caused a certain degree of functional chaos.

\subsubsection{Changes in Residents' Lifestyles and Needs}

During the epidemic period, online shopping and online purchasing businesses are prevalent, and community epidemic prevention requires couriers not to enter, resulting in a large number of express delivery at the door of the community, causing great inconvenience to residents' travel; most residents choose to jog

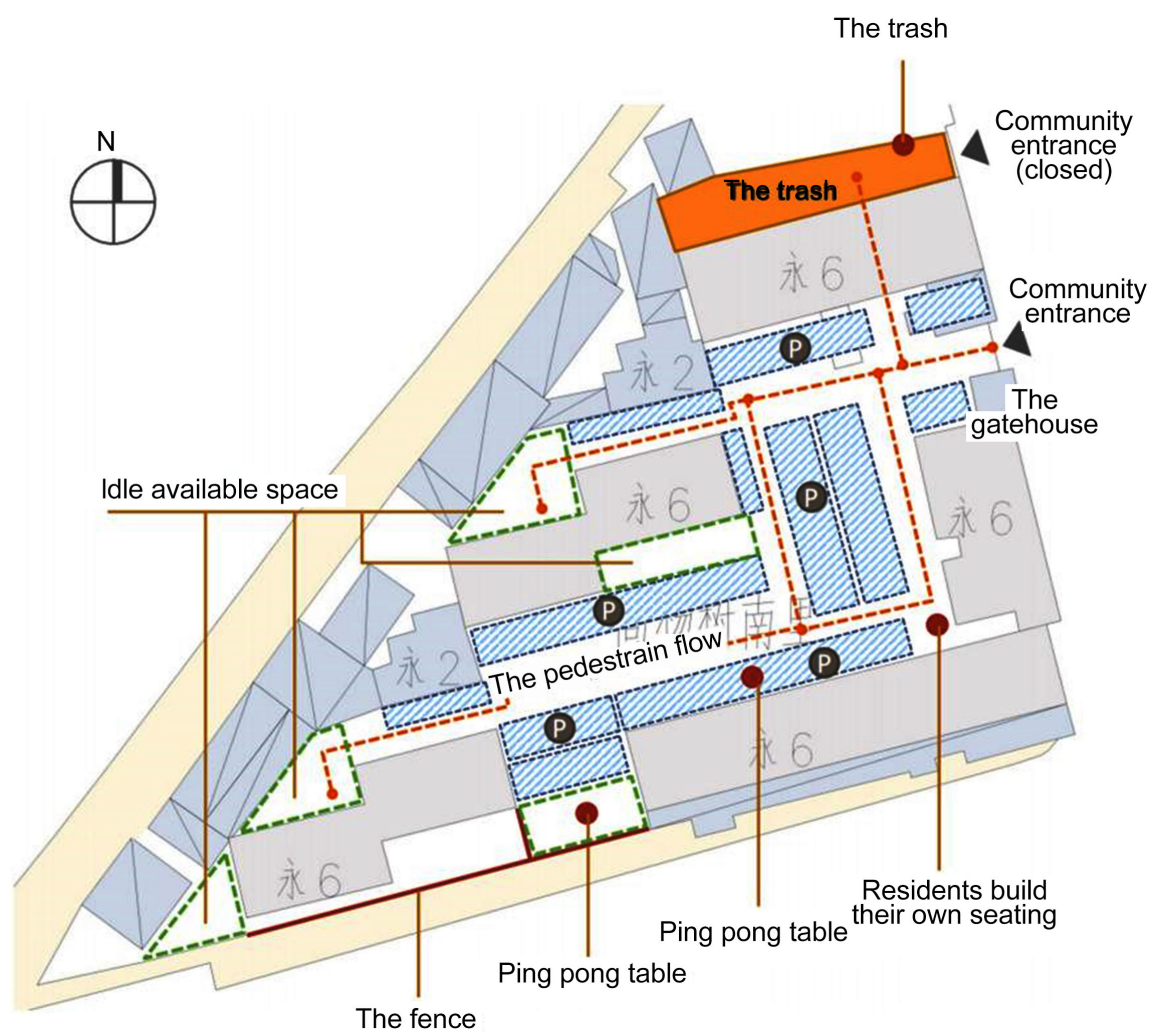

Figure 3. Schematic diagram of transformable space. Image source: self-painted. 
and walk in the community for fitness and fitness. Infection increases the risk; it can be seen from the communication with residents that the common problems of collective housing are becoming more and more catalyzed by the epidemic, and the improvement of public spaces in the post-epidemic period needs to be accelerated.

\subsubsection{The Outdoor Environment Facilities Are Aging, Unable to Meet the Needs of the Post-Epidemic Period}

At the beginning of the design of the collective housing, the main purpose was to meet the residential attributes, the design concept was single, and the construction of flexible community space was not considered. Nowadays, the facilities are outdated and aging, and many designs lack rationality. The independent belt-shaped area on the north side of the community used to be a frequent venue for residents. During the epidemic, you need to go out of the community to enter, and the round-trip temperature measurement caused great inconvenience to residents

\section{The Outdoor Environment Design Countermeasures of Collective Housing from the Perspective of Post-Epidemic}

\subsection{Dividing the Space and Function of Collective Housing from the Perspective of the Combination of Peace and Epidemic}

The planning and design of various public spaces in the community should not only consider daily functional requirements, but also combine various requirements during the epidemic. The transformed community must have the ability to respond to public health disasters. The community environment carries the lives of residents and has a subtle effect on residents' health. The community can organize regular activities to enhance residents' sense of belonging and create a vibrant environment to attract young people, thereby changing the residents' structure and community awareness [7]. The above planning theories need to be practiced in applications and presented in scenarios. It can be said that when theories are applied to generate value, they need to be implemented in application scenarios.

The scene construction for the community $\mathrm{X}$ first starts from the perspective of the combination of peace and epidemic. The residence is the most stable safe house in the epidemic prevention barrier. The community can be compared to a complete set of residential suites. In order to meet the basic living needs of the residents, the residence needs a hallway, Living room, kitchen and bathroom, balcony and bedroom, these functional spaces can correspond to the entrance space, activity space, auxiliary space (fire fighting, power distribution, etc.), green space and living space of the community one by one as shown in Figure 4.

The first is the entrance space, which should meet the current needs of epidemic prevention as the "porch" of the community, and shape it into an anti-epidemic security workstation with community characteristics for daily inspections. The materials are based on the history of the door and window factory 
in the community X. Wooden door frames and bright yellow plastic floors are selected to highlight the entrance space; additional rest seats that can accommodate community workers are added, and take-out and express delivery points are provided to facilitate residents' daily life and provide community epidemic prevention Space as shown in Figure 5.

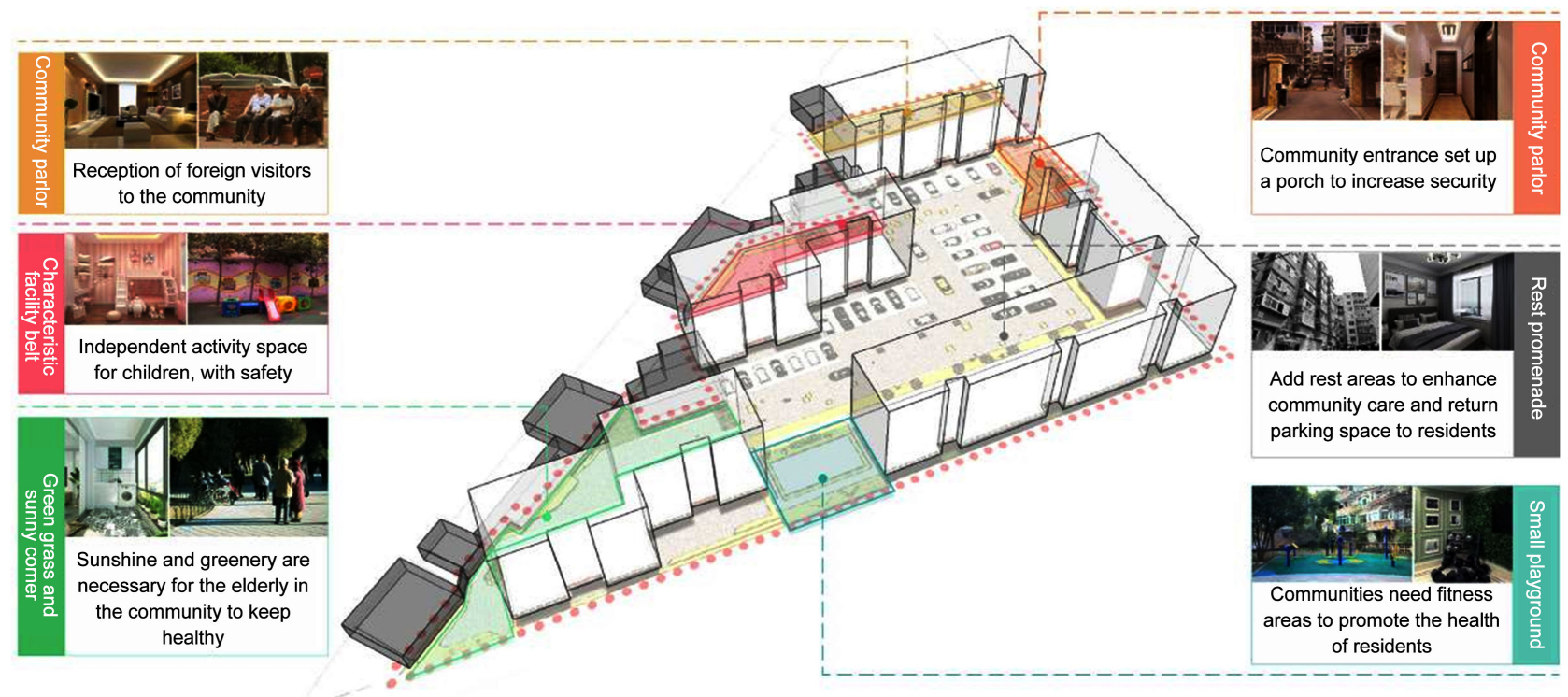

Figure 4. Schematic diagram of cell functional space. Image source: self-painted.
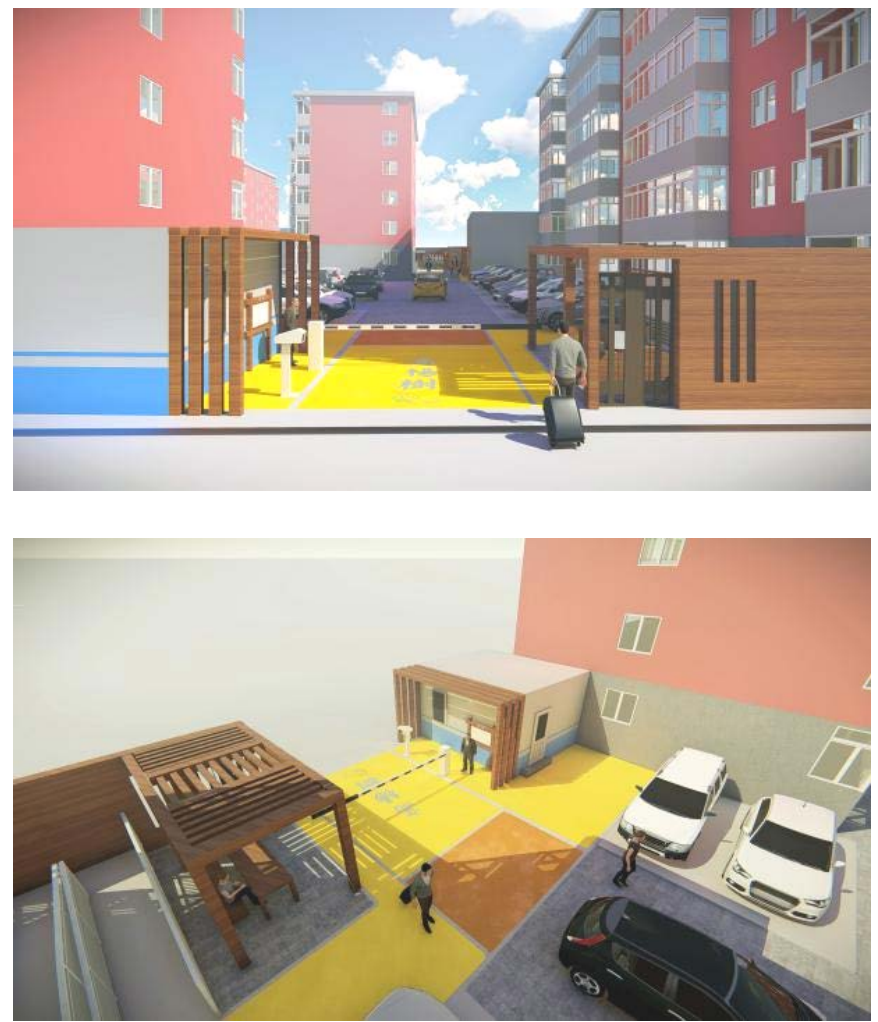

Figure 5. The rendering of the community "porch". Image source: self-painted. 
The additional activity venues added due to the impact of the epidemic include a small community sports field, which is likened to a community "gym". The only complete and square plot in the $\mathrm{X}$ community is planned as a sports field, so that residents can meet their basic fitness needs without going out of the community. Seats are placed on the side to provide residents with a space under the pavilion for communication and interaction, as shown in Figure 6.

Other functional spaces include comparing the activity space to the "meeting room" of the community, taking on the functions of receiving foreign guests, displaying the history and culture of the community, and providing children with independent spaces that are not disturbed by vehicles; auxiliary spaces include the addition and improvement of fire fighting and power distribution facilities; The Sunshine Corner is likened to the "small balcony" of the community. According to the analysis of professional software such as sunshine and wind speed, the public space with the best sunshine and smooth ventilation in the community is extracted as the "Sunshine Corner". The elderly who have nowhere to enjoy the sun are invited to relax and chat here. Physiologically, it promotes physical health; psychologically, it provides social space for elderly people who care at home to reduce loneliness; living space can be likened to a residential "bedroom". The most important thing for the "bedroom" is the sense of security and comfort. To renovate the residential buildings inside, the building itself should be reinforced first, and then access control and barrier-free facilities should be installed to give residents a sufficient sense of security.

\subsection{Refined Design Guarantees Safe Distance in Limited Space}

Keshia Pollack Porter, professor of health policy at Johns Hopkins University, once expressed his views and doubts about social distancing in the post-epidemic period: "This is a good way to rethink how to use public spaces and streets. Opportunity. But can we really find a space where people can gather and socialize safely [8]?"

During the 2020 epidemic, people's social spaces are in a state of "social isolation". From the initial home isolation to the post-epidemic era, a minimum of one meter of "safe social distance" is required to contain the epidemic. This is

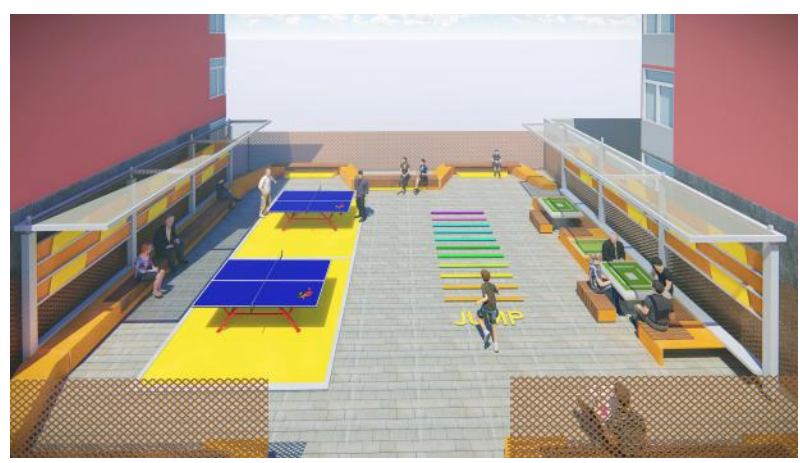

Figure 6. The rendering of the community "gym". Image source: self-painted. 
vigorously advocated in the country. Under the circumstances, residents stayed away from each other while waiting in line for shopping, dining in restaurants, and public transportation. Studies have pointed out that after China has adopted epidemic control measures, the number of people infected with new coronary pneumonia has dropped from 3.8 people to 0.32 people. China's epidemic prevention work is very complete and in place worldwide. However, if you have done a good job of civil air defense, it is difficult to guard against it. The trauma caused by the epidemic is not only reflected in the body, but also an unstable and unsafe social environment for people. People are worried about taking off their masks and worrying about communicating with each other. Being too close and worrying about increasing the risk of infection after stepping out of the safety circle. Some people even have changes in their unhealthy state: anxiety, upset, low mood, depression, fear and other "post-epidemic syndromes", which require targeted measures to resolve and intervene.

There are three main contradictions in the current collective residential space: 1) The physical community public space is not suitable for social communication under safe social distance; 2) People's lack of trust in the public space under the epidemic situation; 3) The basic functions of the community are not satisfied with the current situation Resident needs. Based on these three contradictions, in the practice of refined design of community $\mathrm{X}$, it is necessary to build a rich community external environment under the premise of controlling social distance, and regain residents' emotions and demands for collective housing by way of scene construction.

The "meeting room" of the community is a place for the community to show its spiritual and cultural life to the outside world. Most of the collective housing space is relatively compact, and the independent outdoor space in the north is selected as the community "meeting room", based on the construction of spiritual civilization, to show the historical and cultural context of the community, so as to encourage residents to participate in community life together as shown in Figure 7.

The characteristic "facility belt" is to create a place for children living in a collective house to play, which is not affected by vehicles and has high safety. In the limited space, the children's favorite activity facilities are elaborately arranged and placed side by side to create their own entertainment space for community children, as shown in Figure 8.

Introduce three-dimensional greening to fill the vacant green space in the community, from full of green to sunny. The designable plots of Community $\mathrm{X}$ are mostly long and narrow areas, and proper social distance should be considered during the renovation. In the post-epidemic period, community residents, especially the elderly, lack space for activities, resulting in fewer opportunities for neighborhood communication, which is not conducive to the physical and mental health of the elderly. Therefore, create a community "balcony" combining "green grass room" and "sunshine corner" to give warmth and care to the elderly in the community, as shown in Figure 9. 


\subsection{Shared Smart Facilities Cater to the Lifestyle and Needs of Residents in the New Era}

A community is a small-scale urban cluster, which contains most of the urban
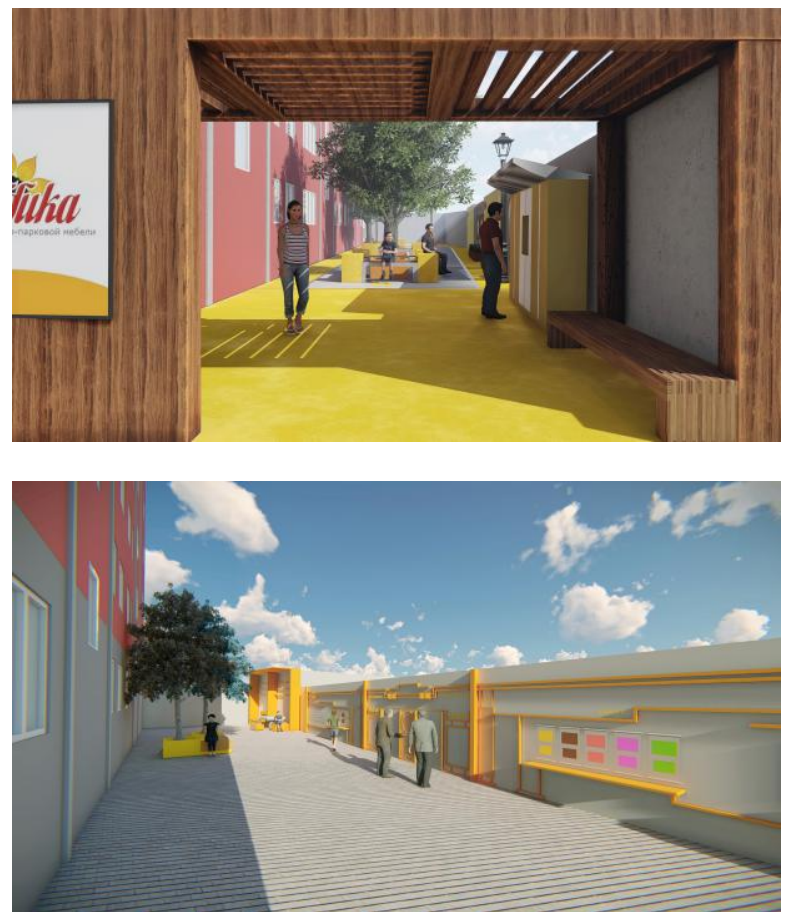

Figure 7. The rendering of the community "meeting room". Image source: self-painted.
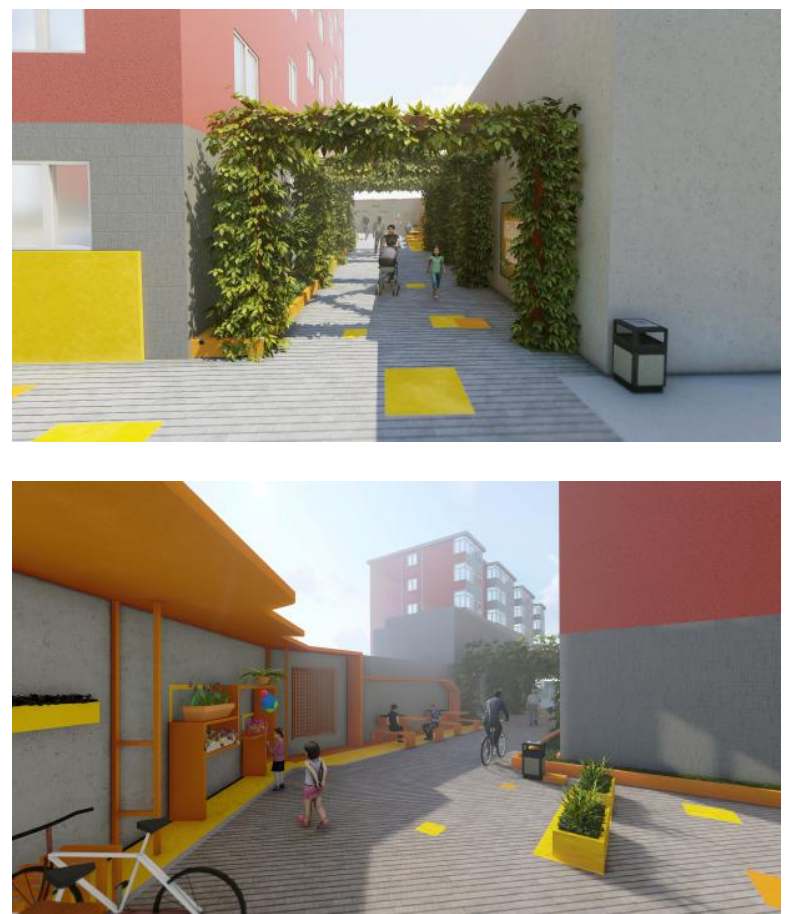

Figure 8. Effect picture of characteristic "facility belt". Image source: self-painted. 

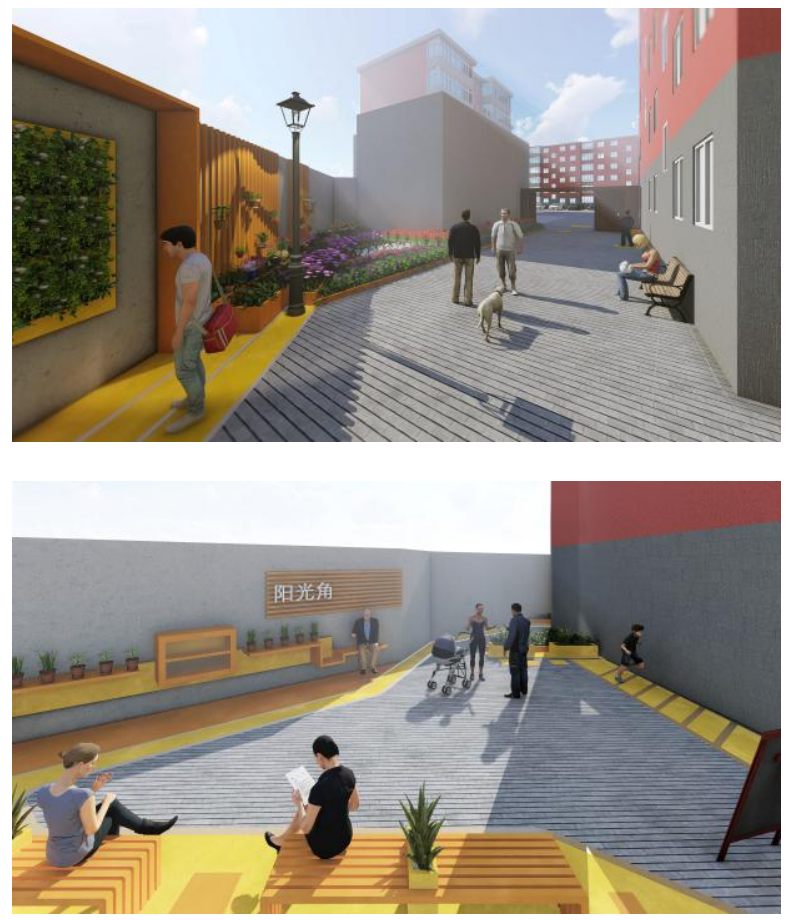

Figure 9. Effect picture of community "balcony". Image source: self-painted.

public space elements, such as public facilities, environmental sketches, and public cultural event venues. The epidemic has compressed the breadth of people's living circles, limiting the frequency and scope of residents' activities within the community level. The community is no longer just a concept of "home" for residents, but a miniature "urban settlement", which requires richer functional places to fill the restricted social space of residents. For cities, shared smart facilities can be seen everywhere, including smart lighting systems, information release systems, video security systems, charging pile systems, supporting lines and pipelines, supporting power lines, supporting communication networks, etc. Shared smart facilities have the advantages of intensive construction, space saving, investment and energy saving, and can play the social benefits of convenient services and refined management [9].

For collective housing below the community level, issues such as limited space in the community, narrow roads, mixed pedestrians and vehicles, and blurred boundaries during the epidemic require manpower and material resources to control and adjust. Therefore, in addition to improving the quality of the space level, it is a general trend to enrich the service scope and functions of integrated residential buildings, and introduce shared smart facilities including smart express cabinets, electric vehicle charging piles, and shared washing machines. Currently, the application standard framework for shared smart facilities at the community level has not yet been established, and it is necessary to improve the design standards of shared facilities in continuous practice.

Nowadays, online purchasing has become an important supplement to the 
daily life of residents in collective housing. Residents are increasingly concerned about the security of the living environment, and they also put forward expectations for the convenience service facilities in the community. The design criteria of "people-oriented, serving the people" should be combined with the current situation, and redefine the community space by sharing and intelligent means, so as to bring more convenience, comfort, safety, reliability, and livability community environment to the residents of the collective housing.

\subsection{Establish a Long-Term Mechanism to Ensure the Operation and Management of the Outdoor Environment of the Collective Housing}

Based on the reverse design of operation and management, there will be many key points that are difficult to consider at the design level, such as how to make management more efficient, how to meet the safety needs of residents at all times, how to achieve long-term operation of convenient commercial services, and also need to consider routines. The difference between period and special period. As operators, real estate or businesses must first consider profitability and balance, residents as users must consider safety and convenience, and the government, as managers, must make overall arrangements and implement toplevel management and control. When seeking a tripartite balance, higher requirements are also placed on planners.

The improvement of the outdoor environment quality of collective residences cannot only rely on one-time capital investment and short-term space renewal, but a long-term, long-term, and sustainable regular maintenance mechanism must be formed according to the income level of the local residents and the actual situation of the community space. Promulgate corresponding environmental conservation and maintenance regulations to clarify the collection and use mechanism of the maintenance fund for the residence itself and public space. Establish a "community autonomy" community affairs organization mechanism and discussion mechanism, and clarify "bottom-up" funding and affairs management methods in community reconstruction. The long-term governance of the collective housing is inseparable from the support of the gradually improved community autonomy mechanism. By establishing an autonomous community organization structure and action mechanism to solve community affairs, it will help to ensure the external environment of the collective housing before, after, and continue to operate. Fund usage and action strategies in maintenance are implemented.

\subsection{Establish Multiple Co-Construction Methods and Methods to Ensure the Renewal Effect of Collective Housing}

The Fourteenth Five-Year Plan of the People's Republic of China proposes that the comprehensive outdoor environment renovation of "collective housing with a construction period of more than 20 years" requires an area of 6 billion square meters to be completed nationwide, and there are approximately 160 million 
square meters in Beijing. For the reconstruction area, China plans to quickly complete the plan within a five-year cycle. Under the premise of very limited time and funds, it is very difficult to carefully craft each reconstruction project. In addition to applying theoretical thinking to the scene, the planner should create it in front of the residents. It is also necessary to build a diversified coconstruction platform, stand with the residents, and jointly achieve the goal. Residents of collective housing may come from the same unit or factory, but with the rapid development of marketization, the once "acquaintance" community has gradually turned into a standardized residential block with apathy and unfamiliar neighbors. The community needs to use multiple co-construction platforms as a catalyst, which can effectively bring neighbors closer in the short term and enhance residents' sense of community responsibility. In the long term, community centers can be used as a network of point-like property management and control, and the social governance network formed by social services can be connected to urban residents. Set up invisible links to achieve regional linkage.

\section{Conclusions}

The improvement of the outdoor environment of collective housing in the postepidemic era is only one part of the comprehensive renovation of old collective housing in China. Comprehensive renovation should develop top-level design from multiple dimensions such as policy guidance, financial support, space creation, management and operation, and subsequent maintenance to achieve this. The activation and circulation of a huge industry with an area of 6 billion are transformed. If the government is unable to achieve a continuous supply of funds, it needs the intervention of social capital, but social capital needs to create production capacity to achieve a balance of funds. The channels include investing in small commercial service facilities in the community and implementing longterm mechanism operations, driven by small businesses. Community vitality, comprehensive renovation work led by the government to improve the outdoor environment of the collective housing, multiple co-construction as a catalyst, close the interactive relationship between residents and collective housing. Government requirements, corporate needs, and residents' demands have all been met, and a virtuous circular system has been created, which enlarges the spatial dimension, enables a single successful case to be put into the area, and forms an overall linkage transformation and improvement, which ultimately completes the country's 14th Five-Year Plan "The proposed 6 billion target".

The limitations of the current research include: insufficient research samples and the project is still under construction, and there is a lack of evaluation after use by residents. The project will continue to follow up. After the completion of the construction, it will continue to increase the depth of research and improve the entire process analysis of the project based on feedback from residents. 


\section{Support}

1) Social Survey of young Teachers in North China University of Technology in 2021; 2) 2021 University student Innovation of North China University of Technology; 3) Youth Fund of National Natural Science Foundation of China: Research on optimization model and reconstruction strategy of built environment of large residential area under the guidance of public health; 4) Project of Beijing Urban Governance Research Base of North China University of Technology in 2021.

\section{Conflicts of Interest}

The authors declare no conflicts of interest regarding the publication of this paper.

\section{References}

[1] Jiang, W., Pan, H., Ye, X., Zhu, X.H. and Lai, S.P. (2020) Set of Epidemic Prevention and Control under the Background of Urban Residential Renovation Strategy Study. Journal of Zhejiang Construction, 37, 1-3+10.

[2] Li, J. and Liu, Y.M. (2020) Residents Participation Physical Activity Is Affected by the City of the Elements of the Built Environment Research Progress. Science and Technology Leader, 38, 76-84.

[3] Cao, X. (2010) Exploring Causal Effects of Neighborhood Type on Walking Behavior Using Stratification on the Propensity Score. Environment and Planning A, 42, 487-504. https://doi.org/10.1068/a4269

[4] Chen, L.Y., Tan, S.H. and Dai, Y. (2017) Community Green Space to People Health Promoting Effect and Planning Strategies. Journal of Architecture and Culture, 2, 184-185.

[5] Dong, J.J. (2010) Based on the Theory of Behavior Change, the City Health Life Unit Build. Harbin Institute of Technology, Harbin.

[6] Zhang, Y.Y., Liu, N.R. and Long, Y. (2020) Evaluation System of the Health Residential Area Building Analysis-Based on the Combination of Urban Planning and Public Health Perspective. Journal of Landscape Architecture, 27, 96-103.

[7] Yu, Y., Wu, X., Tan, X. and Zhao, B. (2020) Flat Plague Toughness of Urban Community Construction and Planning to Deal with. Journal of Planner, 36, 94-97.

[8] Dean, J., et al. (2020) Thinking Relationally about Built Environments and Walkability: A Study of Adult Walking Behavior in Waterloo, Ontario. Health and Place, 64, 102352. https://doi.org/10.1016/j.healthplace.2020.102352

[9] Ma, L., Hong, L. and Zhang, C. (2018) Amy, Loud, Relaxation. Wisdom Shared Infrastructure in the Application of the New Wisdom City Construction. Journal of Small and Medium-Sized Enterprise Management and Science and Technology (the Ten-Day), 12, 171-172. 